\title{
Types, characteristics and environmental degradation of composite materials
}

\author{
Thuraya Abdulrahim Basudan ${ }^{1 *}$, Ghaith Zaki Alsanad², Thamer Saud Alhur ${ }^{2}$, \\ Ahmed Abdulaziz Altamimi ${ }^{2}$, Khalid Abdulrahman Alobaid ${ }^{2}$, Obaid Abdulrahman Alobaid ${ }^{2}$, \\ Nasser Fayez Aldhumayri ${ }^{3}$, Khalid Abdulaziz Alrafie ${ }^{4}$, Turki Mamdouh Alharbi ${ }^{5}$, \\ Ali Abdullah Abuhabshah ${ }^{6}$, Farah Ahmed Sindi ${ }^{7}$
}

\author{
${ }^{1}$ Department of Restorative Dentistry, East Jeddah Hospital, Jeddah, Saudi Arabia \\ ${ }^{2}$ College of Dentistry, University of Hail, Hail, Saudi Arabia \\ ${ }^{3}$ College of Dentistry, Al-Jouf University, Sakaka, Saudi Arabia \\ ${ }^{4}$ General Dentist, West Riyadh Dental Complex, Riyadh, Saudi Arabia \\ ${ }^{5}$ Primary Health Care, Madinah General Hospital, Madinah, Saudi Arabia \\ ${ }^{6}$ College of Dentistry, King Khalid University, Abha, Saudi Arabia \\ ${ }^{7}$ Faculty of Dentistry, King Abdulaziz University, Jeddah, Saudi Arabia
}

Received: 10 August 2021

Accepted: 26 August 2021

\section{*Correspondence: \\ Dr. Thuraya Abdulrahim Basudan, \\ E-mail: tbasudan@moh.gov.sa}

Copyright: () the author(s), publisher and licensee Medip Academy. This is an open-access article distributed under the terms of the Creative Commons Attribution Non-Commercial License, which permits unrestricted non-commercial use, distribution, and reproduction in any medium, provided the original work is properly cited.

\begin{abstract}
Research has offered many advances in the dentistry field and variable types of dental composites have been widely validated to be effectively used with many favorable outcomes. Among the differently reported composites, hybrid ones are the most commonly reported and used in clinical settings. However, the characteristics of these composites vary hugely based on the materials and the environmental factors that they might be potentially exposed to. In this literature review study, we have discussed the types and characteristics of the dental composites, elaborating the effect of different environmental factors on the degradation of the different composite materials. Our results indicate that dental composites are hugely affected by environmental factors as temperature, moisture, chemical reactions and impact blunt. Furthermore, enhancing the quality of the materials by using more flexible approaches might enhance their quality in achieving better outcomes. Moreover, research should be directed within this area to improve the functions of the dental composites and improve the quality of life for the corresponding patients. Composites based on nanotechnology seem promising. However, these are not adequately investigated, and further research is encouraged for adequate validation.
\end{abstract}

Keywords: Dentistry, Composite, Restoration, Degradation, Function

\section{INTRODUCTION}

Many dental composites are nowadays widely available to be used for restoration approaches. Furthermore, in the 1940 s, the primary objective for which composite resin was introduced in the field of dentistry. The objective was to reduce the disadvantages that were reported with acrylic resins that had also replaced silicate cement, which was the only used substance for aesthetic purposes.
Moreover, in 1950, an approach by Buonocore aimed to enhance the quality, effectiveness and adhesion of the acrylic resins by adding orthophosphoric acid to the compound. In the same context, and in 1962, bis-GMA monomers were first introduced by Bowen aiming at enhancing the physical characteristics of the dental acrylic resins, because these previous modalities were associated with the development of polymer chains only. ${ }^{1}$ However, these first initiatives were associated with 
many problems regarding color stability, mixing process, and proportions. $^{2}$ In 1970, further approaches were announced to overcome these disadvantages by introducing electromagnetic radiation polymerization. ${ }^{3}$ Following these approaches, research has offered many advances in this field and variable types of dental composites have been widely validated to be effectively used with many favorable outcomes. Among the differently reported composites, hybrid ones are the most commonly reported and used in clinical settings. ${ }^{4,5}$ However, the characteristics of these composites vary hugely based on the materials and the environmental factors that they might be potentially exposed to. In this literature review study, we will discuss the types and characteristics of dental composites, in addition to elaborating the effect of different environmental factors on the degradation of composites.

This literature review is based on an extensive literature search in Medline, Cochrane, and EMBASE databases which was performed on $5^{\text {th }}$ August 2021 using the medical subject headings $(\mathrm{MeSH})$ or a combination of all possible related terms. ${ }^{6,7}$ This was followed by the manual search for papers in Google Scholar while the reference lists of the initially included papers. ${ }^{8,9}$ Papers discussing the types and characteristics of dental composites were screened for relevant information, with no limitation placed on date, language, age of participants, or publication type.

\section{DISCUSSION}

\section{Types and characteristics}

The classification of dental composites is based on many factors based on their composition, which facilities the identification and use of these composites by dentists for therapeutic purposes and enhances the associated outcomes. ${ }^{10,11}$ Classifications based on filler sizes are the most common among studies in the literature, and they have been extensively discussed by many studies. ${ }^{4,5,12}$ The different types of dental composites are presented in Table 1.

The structure of the dental composites is an important factor to determine the mechanical, physical, and aesthetic characteristics of these composites. It is known that dental composites basically consist of three different chemical materials. These include the inorganic matrix, disperse, or filler phase, the organic matrix or phase, and the organosilane or coupling agent. Moreover, the latter is mainly consisted of a methacrylate group at one end and silane groups at the other end to act as a coupling agent that bonds the organic resin with the filler. The organic matrix is composed in a certain way that enables rapid curing and enhances the lifetime and stability of the dental composites making sure that adequate and favorable outcomes can be obtained. Materials that absorb ultraviolet rays are also involved in the structure of the dental composite which eradicates the harmful effects of the ultraviolet rays and enhances the color stability of the modality. The effectiveness and optimal structures of the monomer systems are also very important in the assessment of the stability of dental composites. For instance, it is acceptable that the rate of shrinkage of the dental composites is inversely proportional to the mean molecular weight of the monomer. Dental resin composites, which are highly viscose. They are generally combined with low viscose monomers as urethane dimethacrylate (UDMA), and ethylene glycol dimethacrylate (EGDMA). Polymerization is an important process to consider because it is usually associated with a degree of shrinkage that might affect the characteristics of dental composites. Accordingly, approaches have been directed to choose monomers with more flexible shrinkage abilities to reduce the negative impact on the overall composite structures and functions. In another context, the mechanical and physical characteristics of the dental composite are mainly dependent on the inorganic filling material. These substances are usually added to the organic material to enhance its physical properties and obtain better outcomes. Some of the reported advantages for using these substances might include reducing the total curing shrinkage, decreasing the thermal expansion, improving handling and aesthetic outcomes, and providing favorable radio-opacity. However, it should be noted that the filling materials are hugely variable according to the morphology, chemical composition, and dimensions. Recent advances were mainly directed to use less hard materials that can induce less wear on the corresponding teeth and enhance the relevant outcomes. Nanotechnological advances were also introduced to this field with favorable outcomes, obtaining a high load, that was previously estimated to be up to $79.5 \%$.

Table 1: Classification and types of composites. ${ }^{13}$

\begin{tabular}{|ll|}
\hline $\begin{array}{l}\text { Composite type } \\
\text { Densified composites }\end{array}$ & Filler \\
\hline $\begin{array}{l}\text { Midway-filled } \\
\text { Ultrafine }\end{array}$ & $<60 \%$ by volume \\
\hline Fine & -Particles $<3$ microgm \\
\hline $\begin{array}{l}\text { Compact-filled }>60 \% \\
\text { by volume }\end{array}$ & $>60 \%$ microgm \\
\hline Ultrafine & -Particles $<3$ microgm \\
\hline Fine & -Particles $>3$ microgm \\
\hline Microfine composites & $\begin{array}{l}\text { Average particle size }=0.04 \\
\text { microgm }\end{array}$ \\
\hline Homogeneous & $\begin{array}{l}\text { Blends of densified and } \\
\text { microfine composites }\end{array}$ \\
\hline Heterogeneous & $\begin{array}{l}\text { Equivalent to what are } \\
\text { termed macrofill composites } \\
\text { Miscellaneous } \\
\text { composites }\end{array}$ \\
\hline $\begin{array}{l}\text { in other classification } \\
\text { composites }\end{array}$ & \begin{tabular}{l} 
Industrial use composites \\
\hline $\begin{array}{l}\text { Fiber-reinforced } \\
\text { composite }\end{array}$
\end{tabular} \\
\hline
\end{tabular}




\section{Environmental degradation}

Many studies in the literature have evaluated the ability of different environmental factors as temperature, moisture, and chemical parameters on the mechanical properties of dental composites and the related outcomes. Furthermore, high-temperature levels can significantly impact the matrix of a dental composite. Besides, it has been noticed that high-temperature levels might also aid to the value of other degradation factors and further impacting of the dental composite. For instance, elevated temperature levels can facilitate chemical reactions by obtaining the optimal temperature levels needed for such reactions to occur. Moreover, previous studies have summarized and indicated the effect of temperature on the oxidation of hydrocarbons and the potential effect on the matrix of dental composites. ${ }^{14,15}$ The formation of free radicals has been noticed with the different forms of energy production and heat transfer. This can result in impaired mechanical properties of the underlying composite as a result of the different reactions that occur with the free radicals and ambient oxygen particles. ${ }^{16}$ Additionally, some studies have evaluated the impact of using aircirculating ovens to obtain thermal oxidation in the employment of isothermal heating. ${ }^{17-21}$ By this method, authors have allowed the presence of atmospheric oxygen within the reaction and potentially preventing degradation as a result of the even distribution of heat and prevention of other parameters that might be responsible for a potential heat transfer. In addition, most of the included studies in the literature have reported a significant reduction in the mechanical properties of different composites as a result of the prolonged exposure to elevated temperature levels. Also, an investigation by Akay and Spratt reported that their used dental composite had a significant reduction in the mechanical properties as a result of thermal aging that induced cracks and mass loss to the composite bodies. ${ }^{19}$ Dao et al also reported that different temperatures were associated with different surface chemistry parameters. ${ }^{22}$ The authors showed that thermal heating at $70^{\circ} \mathrm{C}$ for 7500 hours was associated with minimal changes to the surface chemistry of the dental composites. However, as the authors prolonged the exposure of the dental composites and elevated the temperature, they noticed that changes were deeper into the bulk, indicating the impact of prolonged exposure to excessive heating.

Studies have also evaluated the degradation effects of combined temperature and moisture on the characteristics of the dental composites. These studies have demonstrated that increased rates of degradation of dental composites were associated with increased moisture secondary to high-temperature levels. ${ }^{23-25}$ In this context, a previous investigation by Chateauminois et al evaluated the impact of submerging exposy-glass composites within the water at temperature levels of $30-90{ }^{\circ} \mathrm{C} .{ }^{26}$ The authors showed that the tested composites showed a significant reduction in mass over time and at the different temperatures that were approached by these authors.
Studies have demonstrated the effect of water on composite materials. Water can reach the composite through different approaches including precipitation, bulk liquid, and humidity or fog with many different outcomes among the included studies regarding the severity of impact based on the hygrothermal and hydrothermal affection. Additionally, it has been reported that the route of affection is a major contributor to the severity of the impact and the extent of degradation. ${ }^{27}$ As a result of the potential chemical reactions that occur to the polymer matrix, reduced mechanical properties to the composite materials are expected secondary to moisture, which is an irreversible process. ${ }^{27,28}$ Chain scission might also occur secondary to moisture as what has been reported and observed with ultraviolet radiation and temperature exposure which can significantly induce chain shortening and reduced polymer molecular weight. ${ }^{29}$ Hydrolysis and oxidation reactions are the main causes for these events according to previous studies. ${ }^{30,31}$

It is important to note that the severity of degradation in such events depends on whether water can coordinate and interact with the affinity and reaction sites of the polymer or not. This can be achieved and measured by how well moisture can diffuse within the composite materials. ${ }^{32}$ Accordingly, shrinkage of matrix material during curing should be observed by dentists to determine the effectiveness of the diffusion because in cases of reduced adhesion between the fibers and matrix, capillaries can effectively develop around these fibers. ${ }^{28}$ The swelling coefficient that is due to moisture and to the mechanical properties. Also, it differs between the different composite materials. The material mismatch can lead to strain-induced expansion secondary to moisture, which is similar to the effect of temperature. Although it has been indicated that such events do not necessarily impact material stiffness, it has been indicated that they can lead to the development and propagation of cracks. $^{33,34}$ Accordingly, this might be associated with a significant reduction in strength and can lead to channel formation due to increased moisture ingress. In addition, in a previous investigation of vinyl ester carbon composite, Siriruck and Penumadu evaluated the fatigue ability of these compounds on exposure to seawater and reported that they noticed a $50 \%$ reduction in the fatigue cycles compared to $85 \%$ for single-side exposure and complete immersion, respectively. ${ }^{35}$ Previous studies have also indicated the diffusion rates are higher within the sample's edge than the face..$^{36-38}$

Chemical degradation was also reported among studies in the literature. However, it should be noted that it is usually induced by the same mechanisms that were observed with water and moisture degradation. ${ }^{39,40}$ Temperature elevation might also lead to a significant impact on the severity of degradation and the mechanical properties of the exposed dental composites. However, it should also be noted that the mechanisms of the chemical reactions in inducing degradation are hugely variable because of the variously present chemical reactions. A 
previous investigation by Yoshino et al reported that after immersion the lap joint and neat samples in hydraulic fluid, anti-acing additives, aviation, and water fluids for 10-555 days at different temperatures, the authors have indicated that immersing the samples in hydraulic fluid and anti-acing additives were significantly associated with more increased uptake of mass than what has been observed with water and aviation fuel at the different estimated temperatures. ${ }^{41}$ Besides, the authors also indicated that a 5-7\% mass gain was associated with water immersion in the different temperature levels, and aviation fuel was the most significantly associated with a minimal mass reduction in the room temperature. Another investigation by Landry et al also evaluated the effect of immersing carbon-epoxy composites in hydraulic fluid, distilled water, and de-icing fluid for over one month. ${ }^{42}$ The authors reported that an increase in the rate of exposure delamination was observed to be $4 \%$ only with hydraulic fluid and up to $25 \%$ with water. The characteristics of aramid-epoxy composites were also investigated by d'Almeida after immersion in salt water. ${ }^{43}$ Furthermore, the authors reported that saltwater absorption was more significant than distilled water, which indicated that interlaminar shear distress was notably more reduced with distilled than saltwater. Similar findings were also reported by previous investigations. ${ }^{44-46}$ The impact of low-velocity blunt was also reported by studies in the literature. Back-face matrix cracking, delamination, and fiber failure were all observed events following the impact of these parameters. ${ }^{47,48}$

\section{CONCLUSION}

Dental composites elaborates the effect of different environmental factors on the degradation of the different composite materials. Dental composites are hugely affected by environmental factors as temperature, moisture, chemical reactions and impact blunt. Furthermore, enhancing the quality of the materials by using more flexible approaches might enhance their quality in achieving better outcomes. Research should be directed within this area to improve the functions of the dental composites and improve the quality of life for the corresponding patients. Composites based on nanotechnology seem promising. However, these are not adequately investigated and further research is encouraged for adequate validation.

\section{Funding: No funding sources Conflict of interest: None declared Ethical approval: Not required}

\section{REFERENCES}

1. Bowen RL. Properties of a silica-reinforced polymer for dental restorations. J Am Dental Association. 1963;66:57-64.

2. Kinomoto Y, Torii M, Takeshige F, Ebisu S. Comparison of polymerization contraction stresses between self- and light-curing composites. J dentistry. 1999;27(5):383-9.

3. Hofmann N, Hugo B, Klaiber B. Effect of irradiation type (LED or QTH) on photo-activated composite shrinkage strain kinetics, temperature rise, and hardness. Euro J oral sci. 2002;110(6):471-9.

4. Hervás-García A, Martínez-Lozano MA, CabanesVila J, Escribano BA, Galve FP. Composite resins. A review of the materials and clinical indications. Medicina oral, patologia oral y cirugia bucal. 2006;11(2):E215-20.

5. Ravi RK, Alla RK, Shammas M, Devarhubli A. Dental Composites-A Versatile Restorative Material: An Overview. Indian J Dental Sci. 2013;5(5).

6. Ghozy S, Tran L, Naveed S. Association of breastfeeding status with risk of autism spectrum disorder: A systematic review, dose-response analysis and meta-analysis. Asian $\mathrm{J}$ Psychiatr. 2020;48:101916.

7. Mahmoud AR, Dahy A, Dibas M, Abbas AS, Ghozy S, El-Qushayri AE. Association between sarcoidosis and cardiovascular comorbidity: A systematic review and meta-analysis. Heart Lung. 2020;49(5):512-7.

8. Ghozy S, Nam NH, Radwan I. Therapeutic efficacy of hepatitis B virus vaccine in treatment of chronic HBV infections: A systematic review and metaanalysis. Rev Med Virol. 2020;30(3):e2089.

9. Hashan MR, Ghozy S, El-Qushayri AE, Pial RH, Hossain MA, Al Kibria GM. Association of dengue disease severity and blood group: A systematic review and meta-analysis. Rev Med Virol. 2021;31(1):1-9.

10. Lutz F, Phillips RW. A classification and evaluation of composite resin systems. J prosthetic dentistry. 1983;50(4):480-8.

11. Cramer NB, Stansbury JW, Bowman CN. Recent advances and developments in composite dental restorative materials. J dental res. 2011;90(4):402-16.

12. Zimmerli B, Strub M, Jeger F, Stadler O, Lussi A. Composite materials: composition, properties and clinical applications. A literature review. Schweizer Monatsschrift fur Zahnmedizin=Revue mensuelle suisse d'odonto-stomatologie $=$ Rivista mensile svizzera di odontologia e stomatologia. 2010;120(11):972-86.

13. Willems G, Lambrechts $P$, Braem M, Celis JP, Vanherle G. A classification of dental composites according to their morphological and mechanical characteristics. Dental materials. 1992;8(5):310-19.

14. Hawkins WL. Thermal and oxidative degradation of polymers. Polymer Engineering Sci. 1964;4(3):18792.

15. Bolland J. Kinetics of olefin oxidation. Quarterly Reviews, Chemical Society. 1949;3(1):1-21.

16. Qian S, Igarashi T, Nitta K-h. Thermal degradation behavior of polypropylene in the melt state: molecular weight distribution changes and chain scission mechanism. Polymer Bulletin. 2011;67(8):1661-70. 
17. Tsotsis T. Thermo-oxidative aging of composite materials. J Composite Materials. 1995;29(3):410-22.

18. Akay M, Spratt G, Meenan B. The effects of longterm exposure to high temperatures on the ILSS and impact performance of carbon fibre reinforced bismaleimide. Composites Sci Technol. 2003;63:1053-9.

19. Akay M, Spratt G. Evaluation of thermal ageing of a carbon fibre reinforced bismalemide. Composites Sci Technol. 2008;68:3081-6.

20. Wolfrum J, Eibl S, Lietch L. Rapid evaluation of long-term thermal degradation of carbon fibre epoxy composites. Composites Sci Technol. 2009;69(3):523-30.

21. Hutapea P, Yuan FG. The effect of thermal aging on the Mode-I interlaminar fracture behavior of a hightemperature IM7/LaRC-RP46 composite. Composites Sci Technol. 1999;59(8):1271-86.

22. Dao B, Hodgkin J, Krstina J, Mardel J, Tian W. Accelerated aging versus realistic aging in aerospace composite materials. I. The chemistry of thermal aging in a low-temperature-cure epoxy composite. J Applied Polymer Sci. 2006;102:4291-303.

23. Kumar BG, Singh RP, Nakamura T. Degradation of carbon fiber-reinforced epoxy composites by ultraviolet radiation and condensation. J Composite materials. 2002;36(24):2713-33.

24. Nakamura T, Singh R, Vaddadi P. Effects of Environmental Degradation on Flexural Failure Strength of Fiber Reinforced Composites. Experimental Mechanics. 2006;46:257-68.

25. Guzmán E, Cugnoni J, Gmür T. Multi-factorial models of a carbon fibre/epoxy composite subjected to accelerated environmental ageing. Composite Structures. 2014;111:179-92.

26. Chateauminois A, Vincent L, Chabert B, Soulier JP. Study of the interfacial degradation of a glass-epoxy composite during hygrothermal ageing using water diffusion measurements and dynamic mechanical thermal analysis. Polymer. 1994;35(22):4766-74.

27. Lopes Fernandes R, De Moura M, Moreira R. Effect of moisture on pure mode I and II fracture behavior of composite bonded joints. International Journal of Adhesion and Adhesives. 2016;68.

28. Mallick P. Failure of polymer matrix composites (PMCs) in automotive and transportation applications. In: Failure Mechanisms in Polymer Matrix Composites. Elsevier; 2012:368-92.

29. Spencer P, Ye Q, Park J. Adhesive/Dentin interface: the weak link in the composite restoration. Ann Biomed Eng. 2010;38(6):1989-2003.

30. Chatterjee A, Gillespie Jr JW. Moisture absorption behavior of epoxies and their S2 glass composites. J appl polymer sci. 2008;108(6):3942-51.

31. Xiao G, Shanahan M. Irreversible effects of hygrothermal aging on DGEBA/DDA epoxy resin. J Appl Polymer Sci. 1998;69(2):363-369.

32. Colombini D, Martinez-Vega J, Merle G. Dynamic mechanical investigations of the effects of water sorption and physical ageing on an epoxy resin system. Polymer. 2002;43:4479-85.

33. Spencer P, Jonggu Park QY, Misra A. Durable bonds at the adhesive/dentin interface: an impossible mission or simply a moving target? Brazilian dental sci. 2012;15(1):4-18.

34. Sarikaya R, Song L, Yuca E. Bioinspired multifunctional adhesive system for next generation bio-additively designed dental restorations. J mechanical behavior of biomedical materials. 2021;113:104135.

35. Siriruk A, Penumadu D. Degradation in fatigue behavior of carbon fiber-vinyl ester based composites due to sea environment. Composites Part B Engineering. 2014;61:94-8.

36. Choi H, Ahn K, Nam J-D, Chun H. Hygroscopic aspects of epoxy/carbon fiber composite laminates in aircraft environments. Composites Part A: applied science and manufacturing. 2001;32(5):709-20.

37. Muñoz E, Garcia-Manrique J. Water Absorption Behaviour and Its Effect on the Mechanical Properties of Flax Fibre Reinforced Bioepoxy Composites. Int J Polymer Sci. 2015;2015:1-10.

38. Santos C, Clarke R, Braden M, Guitián F, Davy KWM. Water absorption characteristics of dental composites incorporating hydroxyapatite filler. Biomaterials. 2002;23:1897-904.

39. Yap AU, Tan SH, Wee SS, Lee CW, Lim EL, Zeng KY. Chemical degradation of composite restoratives. J oral rehabilitation. 2001;28(11):1015-21.

40. Yap AU, Chew CL, Ong LF, Teoh SH. Environmental damage and occlusal contact area wear of composite restoratives. J oral rehabilitation. 2002;29(1):87-97.

41. Sugita Y, Winkelmann C, La Saponara V. Environmental and chemical degradation of carbon/epoxy lap joints for aerospace applications, and effects on their mechanical performance. Composites Sci Technol- composites sci technol. 2010;70:829-39.

42. Landry B, LaPlante G, LeBlanc LR. Environmental effects on mode II fatigue delamination growth in an aerospace grade carbon/epoxy composite. Composites Part A: Applied Science and Manufacturing. 2012;43(3):475-85.

43. d'Almeida JRM. Effects of distilled water and saline solution on the interlaminar shear strength of an aramid/epoxy composite. Composites. 1991;22(6):448-50.

44. Chen H, Miao M, Ding X. Influence of moisture absorption on the interfacial strength of bamboo/vinyl ester composites. Composites Part A: Applied Science and Manufacturing. 2009;40(12):2013-9.

45. Yap AU, Wattanapayungkul P, Chung SM. Influence of the polymerization process on composite resistance to chemical degradation by foodsimulating liquids. Operative dentistry. 2003;28(6):723-7. 
46. Yap AU, Soh MS, Han TT, Siow KS. Influence of curing lights and modes on cross-link density of dental composites. Operative dentistry. 2004;29(4):410-15.

47. Yu C, Abbott P. Responses of the pulp, periradicular and soft tissues following trauma to the permanent teeth. Aus Dental J. 2016;61(S1):39-58.

48. Betancourt DE, Baldion PA, Castellanos JE. ResinDentin Bonding Interface: Mechanisms of Degradation and Strategies for Stabilization of the
Hybrid
Layer.
Int
J
Biomaterials.

2019;2019:5268342.

Cite this article as: Basudan TA, Alsanad GZ, Alhur TS, Altamimi AA, Alobaid KA, Alobaid OA et al. Types, characteristics and environmental degradation of composite materials. Int J Community Med Public Health $2021 ; 8: 5054-9$. 